\title{
CONSTRUAL LEVEL EFFECTS IN SPONSORSHIP ANNOUNCEMENTS
}

\author{
Tobias Schaefers, EBS Business School, Germany \\ Joe Cobbs, Northern Kentucky University, USA \\ Mark D. Groza, Northern Illinois University, USA
}

\begin{abstract}
Corporate financial contributions fund many events and organizations, such as art exhibits, concerts, and sports teams. Often corporations make such contributions in exchange for the right to affiliate with the sponsored event or organization. Sponsorship is thus regarded as a marketing communication instrument. Besides communicating via sponsorship, sponsors and sponsored entities also communicate about a sponsorship. Such "sponsorship-linked marketing" is especially common when announcing the initiation of a sponsorship. In this context, one challenge is how best to communicate the relationship created via corporate sponsorships. However, research on the influence of sponsorship announcements has uncovered mixed results and suffers from two shortcomings. First, previous studies have only considered the announcement of sponsorships at a generic level, while ignoring the potential for variation in how a sponsorship is publicly announced (i.e., the composition of announcements). Second, scholars have emphasized investors' reaction to announcements while overlooking any potential effects on consumers, who are a more likely target for sponsorship communication. In the present study, we therefore investigate how different types of sponsorship announcements influence consumers' perceptions of the sponsoring firm. Specifically, based on Construal Level Theory (CLT), we conducted the first of a series of experiments to investigate how the concreteness of the information contained in an announcement influences consumers' responses to the sponsorship.
\end{abstract}

Construal level theory suggests that individuals evaluate information with different degrees of abstraction. High-level construals are simple mental representations and only extract the most important available information from a situation. These construals consist of general features of the event, and thus deemphasize unique and detailed features. Meanwhile, low-level construals tend to be more concrete and contextualized features of the event. While low-level construals are richer and more detailed, they are also less structured and less parsimonious than high-level construals. Moreover, CLT suggests that individuals differ in their mental construction of identical information, known as Personal Level of Construal (PLC).

To meet our purpose of understanding how sponsorship announcements influence consumers, we apply CLT to the information content of announcements. We assess the impact of individuals' construal predisposition to abstract (high-level) or concrete (low-level) mental construction and derive three hypotheses about the effects of different levels of information construal in communication about sponsorships. Specifically, we anticipate that overall, an announcement containing more concrete details about a sponsorship (i.e., low levels of construal) will result in more positive outcomes for both the sponsoring brand (H1) and sponsored event (H2) when compared to a more abstract announcement. Moreover, we predict an interaction effect between the construal level of the sponsorship announcement and respondents' PLC (H3). This proposition is based on the idea that whether or not information presented about a sponsorship matches the individual's PLC will influence the extent of information processing, with mismatches sparking more extensive processing. We thus assume that consumers with a high (low) PLC will evaluate the sponsoring brand and the sponsored event more (less) positive when faced with a concrete sponsorship announcement than when faced with an abstract sponsorship announcement.

To test the proposed hypotheses we conducted an experiment that manipulated the construal level of a sponsorship announcement (abstract/concrete) between subjects. Results indicate that an announcement of a lower construal level (i.e., more concrete) leads to more positive evaluations of both the sponsoring brand and the sponsored event, thereby supporting hypotheses $\mathrm{H} 1$ and $\mathrm{H} 2$. Regarding the hypothesized interaction effect, for abstract thinkers, concrete announcements did indeed lead to a more positive attitude toward the sponsor, a higher trust in the sponsor, a higher willingness to recommend the sponsor, and a higher purchase intention of the sponsor, as well as a more positive attitude toward the sponsored event and a higher trust in the sponsored event, thereby supporting H3. Concrete thinkers' evaluation of the sponsoring brand and the sponsored event, however, did not show any significant differences based on the construal level of the announcement. This finding requires further consideration of concrete thinkers' processing of information at different levels of abstraction.

The results of this first experiment demonstrate the relevance of considering CLT in sponsorship-linked communications. Presenting content at a low level construal is preferable to more abstract information. The findings in this initial study also suggest that individuals interpreting the concrete announcements with a higher level construal react more favorably toward the sponsoring brand and, to some extent, the sponsored event as well. As a result, manipulating an individual's construal level (through temporal or social distance) could be useful for marketers engaged in sponsorship communications. 